\title{
Triterpenes from the genus Ficus and Their Bioactivities
}

\author{
Qinru Zhou, Na Mao, Yan Chen, Shiquan Gan, Linjing Wu, Xiangchun Shen, ${ }^{*}$ and Nenling Zhang* \\ Department of Natural Medicinal Chemistry (State Key Laboratory of Functions and Applications of \\ Medicinal Plants, High Efficacy Application of Natural Medicinal Resources Engineering Center of \\ Guizhou Province, High Educational Key Laboratory of Guizhou Province for Natural Medicinal \\ Pharmacology and Drug Ability, Union Key Laboratory of Guiyang City-Guizhou Medical University, \\ Key Laboratory of Optimal Utilization of Natural Medicine Resources), School of Pharmaceutical \\ Sciences, Guizhou Medical University, Guiyang, Guizhou 550025, China
}

Email: shenxiangchun@126.com (X.S.), nenlingzhang@foxmail.com (N. Z.)

\begin{abstract}
Triterpenoids exist commonly in the genus Ficus. Till now, ninety-seven triterpenes have been isolated from the genus Ficus. The bioactivities of five triterpenes including maslinic acid, oleanolic acid, lupeol, betulinic acid and ursolic acid have been studied extensively. Herein, we provide an overview of triterpenes in the genus Ficus and their various bioactivities.
\end{abstract}

Keywords Ficus, triterpenoids, oleanolic acid, bioactivities

\section{Introduction}

The genus Ficus belongs to Moraceae that comprises about 1000 species, and it distributes mainly in the tropical and semitropical area. This genus can be deciduous or evergreen trees, shrubs, herbs, climbers or creepers, ${ }^{[1]}$ and their medicinal plants are often used in traditional folk medicine to treat pneumonia, cancer, tonsillitis, diarrhea, leukoderma, and cough. ${ }^{[2]}$ Previous phytochemical studies on Ficus genus have revealed the presence of coumarins, flavonoids, and triterpenoids. Triterpenoids, whose basic structures are usually established by thirty carbons with five isoprene units, exist widely in the genus Ficus and exhibit antineoplastic, antiviral, antibacterial, and anti-inflammatory activities. In this minireview, we summarized the triterpenes from the genus Ficus and their bioactivities.

\section{Triterpenoids isolated from the genus Ficus}

Up to now, twelve species of the genus were reported of the presence of triterpenes. Kuo group investigated $F$. microcarpa extensively and isolated thirty-five triterpenes (1-35) from its aerial roots and nine triterpenes (36-44) from its bark (Figure 1). ${ }^{[3-8]}$ Among these triterpenes, compounds $1-14$ belong to taraxastane-type. Compounds 17 and 18 were determined as rare 13,27-cycloursane-type, and compounds 22 and 25 were elucidated by NMR and further confirmed by $X$-ray crystallography as $3 \beta$-acetoxy- $1 \beta, 11 \alpha$-epidioxy-12-ursene and $3 \beta$-acetoxy-18 $\alpha$-hydroperoxy-12-oleanen-11-one. Higa et al. ${ }^{[9]}$ isolated seven triterpenes from the enthanol extract of $F$. microcarpa leaves and elucidated them as taraxerol (45), glutinol (46), betulinic acid (47), oleanolic acid (48), epifriedelinol (49), friedelin (50), and lupeol acetate (51). From the fresh leaves and stems of $F$. thunbergii, Kitajima et al. ${ }^{[10]}$ obtained rhoiptelenol (52), $\alpha$-amyrin (53), $\alpha$-amyrin acetate (54), ursolic acid (55) and 3a-hydroxyisohop-22(29)-en-24-oic acid (56). From the fruit of $F$. pumila $L$, two cycloartane-type triterpenoids (57 and 58), six acetylated dammarane-type triterpenoids (59-62), one euphane-type triterpenoid (63) and another two triterpenes (64 and 65) were isolated from its methanolic extract. ${ }^{[11,12]}$ From the leaves or stems of $F$. pumila $L$,
$11 \alpha$-hydroxy- $\beta$-amyrin (66) and a new neohopane $(3 \beta, 29$ dihydroxy-17- $\alpha$-methylhop-13(18)-ene, 67) were obtained by silica gel chromatography. ${ }^{[13,14]}$ From its fresh leaves, compounds $68-73$ were isolated from the ether extract. ${ }^{[15]}$ Tuyen et al. ${ }^{[16]}$ investigated the bark of $F$. fistulosa and purified seven triterpenes $(\mathbf{7 4 - 8 0})$ from its $\mathrm{MeOH}$ extract by silica gel column chromatography and HPLC. The fractionation and purification of the leaf, stem bark and fruit extracts of $F$. natalensis led to the isolation and identification of the triterpenes $(\mathbf{8 1 - 8 3 )}){ }^{[17]} \mathrm{A}$ novel lanostane derivative (lanost-20en-3 $\beta$-acetate, 84), along with three other triterpenes (85-87) were isolated and characterized from the root bark of $F$. racemosa. ${ }^{[18]}$ From the fresh stem of $F$. spetica, a rare triterpene skeleton derivative, 13,27-cycloursan-3 $\beta$-yl-acetate (88) was isolated from natural sources for the first time. ${ }^{[19]}$ Study on the fresh and undried leaves of $F$. carica afforded baurenol (89). ${ }^{[20]}$ From the air-dried powdered leaves of $F$. pandurata Hance, isolation and purification of its ethyl acetate-soluble fraction afforded $\beta$-amyrone (90) and $2 \alpha, 3 \alpha$-dihydroxy-lup-20(29)-en-28-oate (91). ${ }^{[21]}$ A new antimicrobial triterpenic acid named as $(9,11),(18,19)$-disecoolean12-en-28-oic acid (92) was afforded from the leaves of $F$. benjamina. $^{[22]} 3-O-[\beta-D$-glucopyranosyl]-quinovic acid-28-O[ $\beta$-L-rhamnopyranosyl] ester (93) was isolated from the aerial roots of $F$. elastic. ${ }^{[23]}$ Investigation on the $\mathrm{EtOH}$ extract of the air dried stems of $F$. tsiangii afforded 3-acetoxy-12-oleanene11-ketone (94), 3-acetoxy-lup-12,20(29)-diene (95). ${ }^{[24]}$ Epilupeol acetate (96) was isolated and identified from $F$. drupacea $\mathrm{L}$ with antifungal activities against Aspergillus versicolor and $A$. ochraceuswere. ${ }^{[25]}$ A novel triterpene lactone was isolated and determined as moretenolactone (97) from the leaves of $F$. insipida. ${ }^{[26]}$

\section{Bioactivities of triterpenes from the genus Ficus}

Triterpenoids have extensive biological activities. Researches show that they possess antineoplastic, antidiabetic, antibacterial, antiviral, antiparasitic, antifertility, hepatoprotective and anti-inflammatory activities.

\section{Antineoplastic activity}

Maslinic acid (43) exerted cytotoxicity to A549 cells by 
inducing mitochondrial apoptosis and suppressing HIF-1 $\alpha$ expression under normoxic and hypoxic conditions. ${ }^{[27]}$ Oleanolic acid (39) inhibited the proliferation of T24 cells of human bladder cancer through inhibiting Akt/mTOR/S6K and ERK1/2 signal pathway. ${ }^{[28]}$ Betulinic acid (38) decreased the cells in the S-phase and increased the cells in the G2-phase, causing the arrest of cells in the G2-phase, thus inhibited the proliferation of triple-negative breast cancer cells. ${ }^{[29]}$

\section{Antidiabetic activity}

A triterpene, $\alpha$-amyrin acetate (54) from the fruits of $F$. remosa was evaluated for antihyperglycemic activity in STZ-S model at the dose of $100 \mathrm{mg} / \mathrm{kg}$ and found to lower the blood glucose levels by $18.4 \%$ and $17 \%$ at 5 and $24 \mathrm{~h}^{[30]}$ Oleanolic acid (39) could enhance glucose-stimulated insulin secretion and cell proliferation in insulinoma cells. ${ }^{[31]}$ Ursolic acid (55) slowed the development of diabetic nephropathy and decreased glomerular mesangial cells hypertrophy and proliferation through inhibiting p85PI3K-pAkt-pmTOR signal pathway caused by up-regulating miRNA-21 and downregulating PTEN protein. ${ }^{[32]}$

\section{Hepatoprotective activity}

Lupeol (80) ameliorated GaIN/LPS-induced liver injury through inhibiting IRAK-mediated TLR inflammatory signaling. ${ }^{[33]}$

\section{Anti-inflammatory activity}

Lupeol (80) protected against LPS-induced microglial neuroinflammation via inhibiting the P38-MAPK and JNK pathways, thus having the therapeutic potential to treat various neuroinflammatory disorders. ${ }^{[34]}$ Maslinic acid (43) may protect neural cells by promoting synaptogenesis and axonal regeneration through regulating Akt/GSK-3 $\beta$ signaling pathway. ${ }^{[35]}$

\section{Antibacterial activity}

Fontanay et al. ${ }^{[36]}$ investigated the antibacterial activities of betulinic acid (38), oleanolic acid (39) and ursolic acid (55). Their study showed that betulnic acid didn't have antibacterial activity (38), whereas oleanolic acid (39) and ursolic acid (55) showed a moderate to strong antibacterial activity against Gram-positive bacteria through inhibiting the expression of peptidoglycan biosynthesis-related genes of S. mutans UA159 at the transcriptional level. Antibacterial and antifungal activities of maslinic acid (43) were evaluated by the agar well diffusion method. ${ }^{[37]}$ The results showed that it inhibited moderately on Aspergillus flavus and Ustilago maydis.

\section{Antiviral activity}

Betulinic acid (38) prevented HCV replication by suppressing the NF-KB and ERK1/2-mediated COX-2 pathway. ${ }^{[38]}$ Oleanolic acid (39) inhibited the secretion of HBsAg and $\mathrm{HBeAg}$ in $\mathrm{HepG}$ 2.2.15 cell line, indicating potential HBV inhibitory activity. ${ }^{[39]}$

\section{Antiparasitic and anti-HIV activity}

Yamamoto et al. ${ }^{[40]}$ assayed the activity of oleanolic acid (39) and ursolic acid (55) in experimental cutaneous leishmaniasis (in vitro and in vivo). They concluded that oleanolic acid (39) eliminated leishmania in the promastigote form, whose mechanism may be associated with programmed cell death.

Among HIV-1 reverse transcriptase (RT)-associated functions, DNA polymerase and Ribonuclease $\mathrm{H}(\mathrm{RNase} \mathrm{H})$ are both essential for HIV replication. Esposito et al. ${ }^{[41]}$ showed that betulinic acid (38) can impair the function of ribonuclease $\mathrm{H}$ (RNaseH), which is related to HIV-1 reverse transcription.
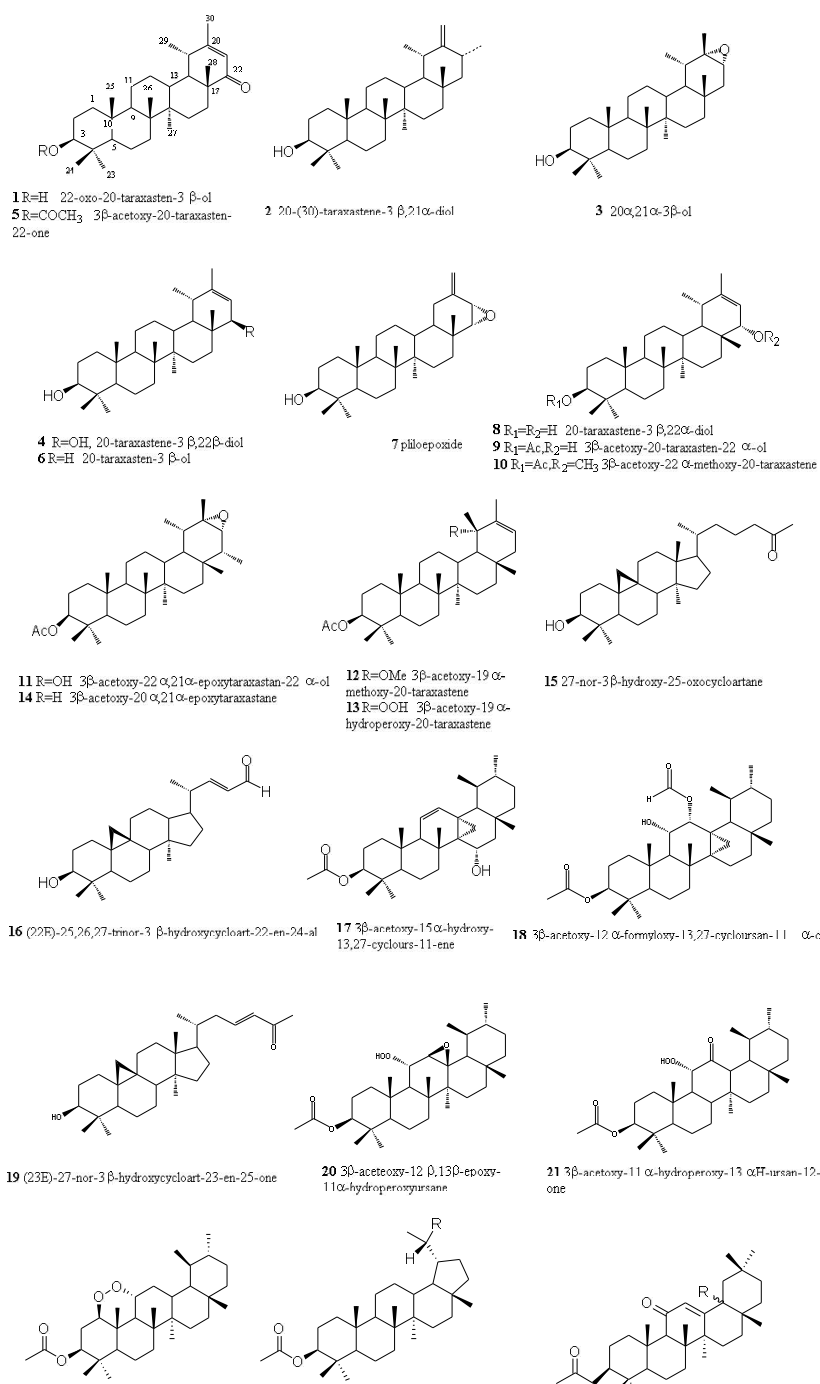

one
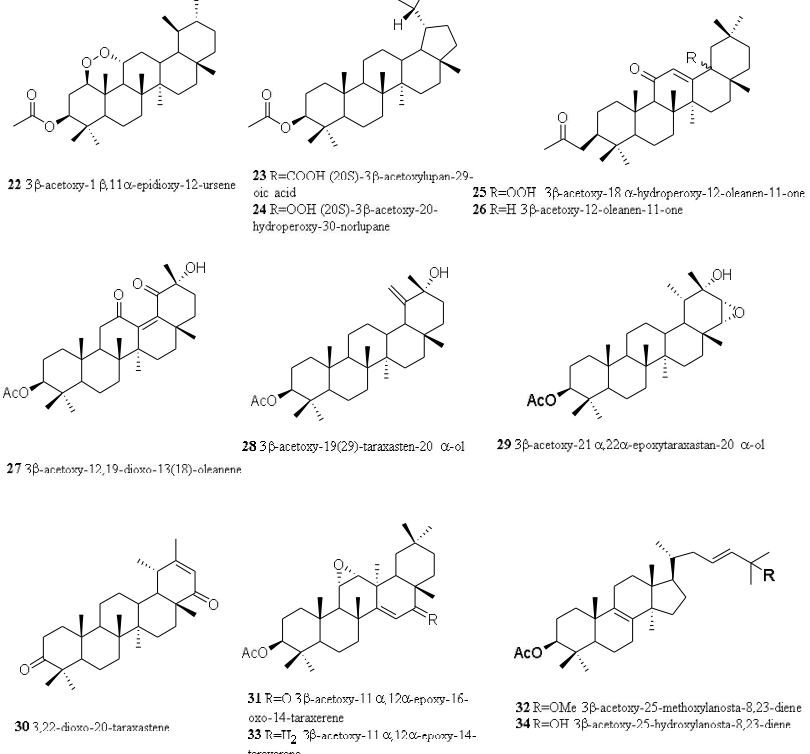

30 3,22-dioxo-2n-taraxanatert

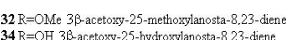
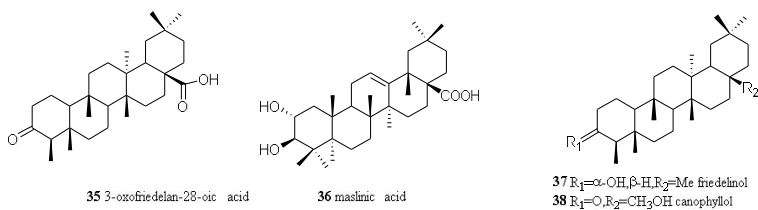


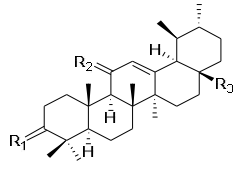

$39 \mathrm{R}_{1}=\beta-\mathrm{OAc} \mathrm{R}_{2}=\mathrm{O} \mathrm{R}_{3}=$ Me 3 $\beta$-acetoxy-12-ursen-11${ }_{40} R_{1}=R_{2}=O R_{3}=$ Me 12-ursene-3,11-dione

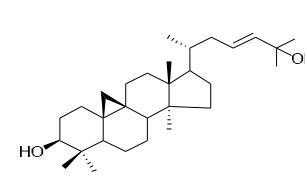

42 ryclongrt?

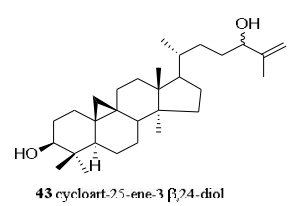

(4taxaxerne

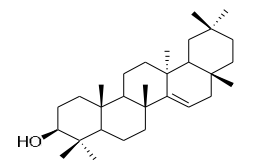

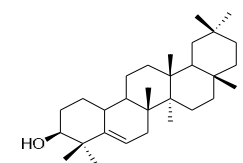

45 taraxerol 46 glutinnl<smiles>CC(C)C1CCC2(O)CCC3C4CCC5C(C)CCC5(C(C)C)C4CCC3C12C</smiles>

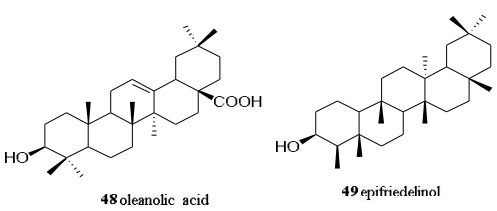<smiles>C=C(C)C1CCC2(C)C3CCC4(C)C5CCC(OC)C(C)C5CCC4(C)C3CCC12C</smiles>

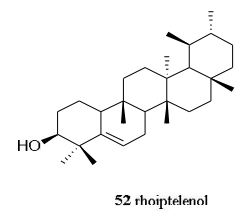

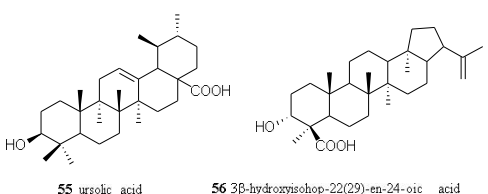
55 ursolic acid

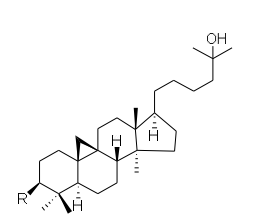

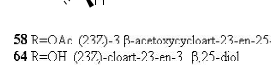

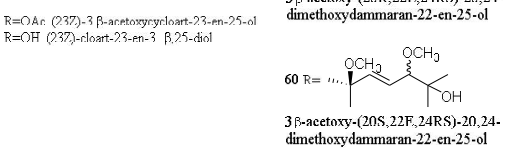

(1)
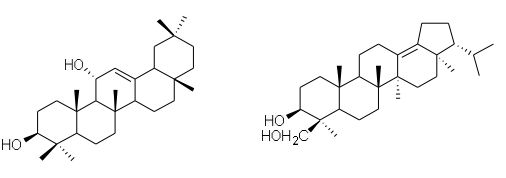

(coOH

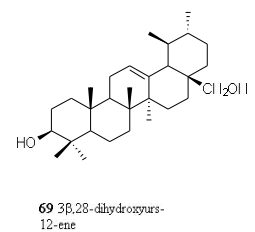

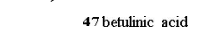

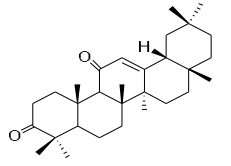

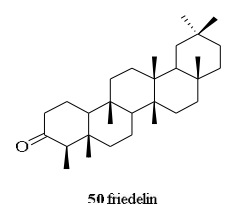

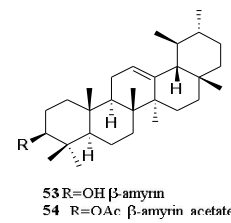

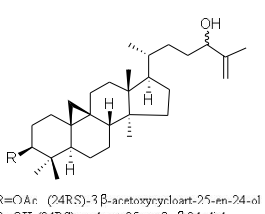

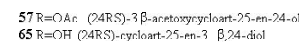<smiles>CC(=O)C1CCC2C3CCC4(C)C(O)CCC1C2(C)CCC34</smiles>

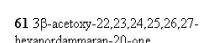
hexanordemmaran-20-one

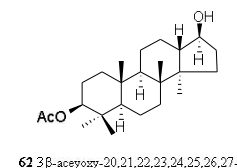

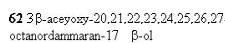
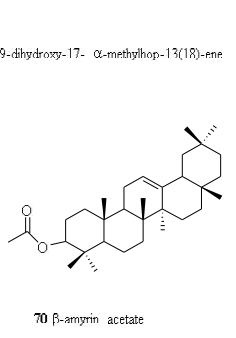

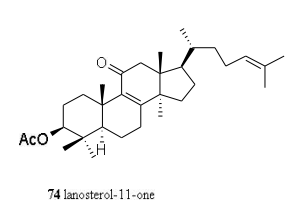

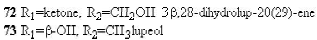

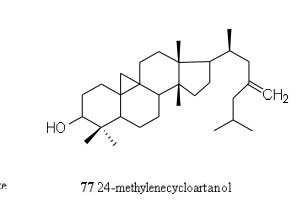

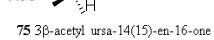

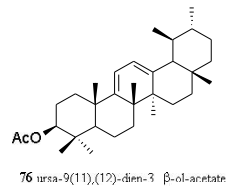

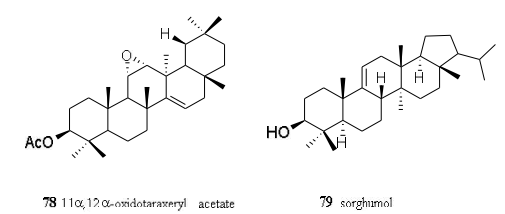<smiles>CC(=O)C1CCC2C1CCC1C2CCC2(C)C(C)CCC12</smiles>

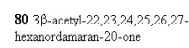
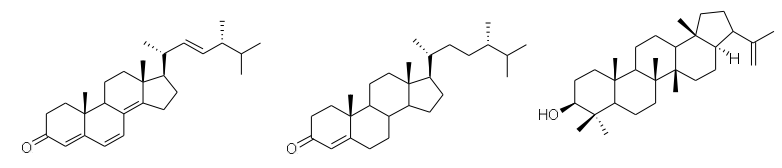

81 ergasta-4.6.8.(14),27-tetrarne-3-3-ne

82 stimma-4-ente-3-one 83 39-hydromy-21 19-H-hop-2):2991-ene.

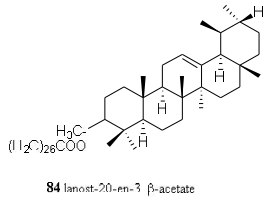<smiles>CC(C)=CCC/C(C)=C/CC/C(C)=C/CCC1=CCCC2(C)C(C)CCCC12C</smiles><smiles>CC(C)CCCC1CCC2C1CCC1C2CCC2C1CC[C@H]1C2CCC(C)C1(C)C</smiles><smiles>CC(=O)OC1CCC2(C)C(C)CCC3C2CCC2=C(CCC23C)C2CCCC(C)C12</smiles>

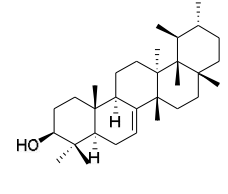

$87,2,4,7$-dihydmparkenl acetate

88 13, 7-eycloursan-3P-yl-acetate

89 baurenol

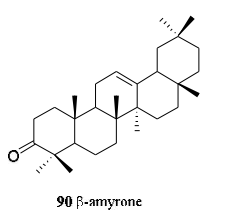

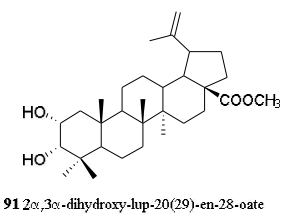

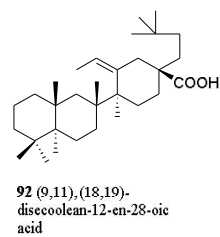

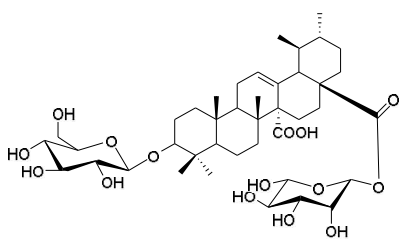

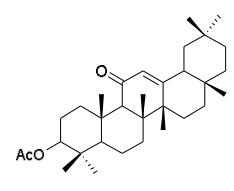

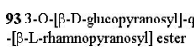
943-acetoxy-12-oleanene-11-keton

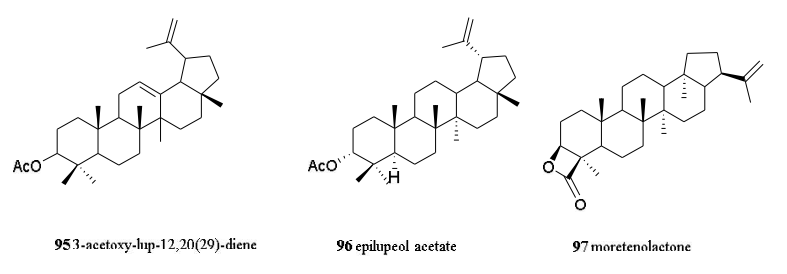

Figure 1 Structures of triterpenoids from the genus Ficus. 


\section{Conclusions and Perspectives}

The plants from the genus Ficus have a long history in medicinal use. With the improvement of modern instruments and experimental techniques, many chemical constituents have been isolated and elucidated from the genus Ficus and some of them have been bio-evaluated. This minireview summarizes 97 triterpenoids (the richest constituents) and their bioactivities as antidiabetic, antineoplastic, anti-inflammatory and antibacterial from twelve species of the genus Ficus. However, as we read the published papers, we found that most pharmacological assays still used their crude extracts and the chemical constituents accounting for the bioactivities have yet to be known. In order to get drug candidates from the genus Ficus, the chemical constituents of most plants of the genus and their activities still need to be investigated extensively in future.

\section{Acknowledgement}

This work was supported by the Social Development Supportive Program of Science \& Technology Department of Guizhou Province (No. [2018]2767), the National Natural Science Foundation of China (No. 81860612), the Joint Fund by Science \& Technology Bureau of Guiyang and Guizhou Medical University (No. [2017]30-37), and the National Undergraduate Training Programs for Innovation and Entrepreneurship (No. 201610660024).

\section{References}

[1] Delectis Florae Reipublicae Popularis Sinicae Agendae A-cademiae Sinicae Edita, Florae Reipublicae Popularis Sinicae, Vol. 23, Science Press, Beijing, China, 1998.

[2] Jiangsu Institute of Botany, Institute of Materia Medica Chinese Academy of Medical Sciences, Kunming Institute of Botany Chinese Academy of Sciences, XinHua BenCaoGangYao (II), Shanghai Science and Technology Press, Shanghai, China, 1991.

[3] Chiang, Y. M.; Kuo, Y. H. J. Nat. Prod. 2000, 63, 898.

[4] Chiang Y. M.; Chang J. Y.; Kuo C. C.; Chang C. Y.; Kuo Y. H. Phytochemistry 2005, 66, 495.

[5] Chiang, Y. M.; Kuo, Y. H. J. Nat. Prod. 2001, 64, 436.

[6] Chiang, Y. M.; Su, J. K.; Liu, Y.H.; Kuo, Y. H. Chem. Pharm. Bull. 2001, 49, 581

[7] Kuo, Y. H.; Chiang, Y. M. Chem. Pharm. Bull. 1999, 47, 498.

[8] Kuo, Y. H.; Li, Y. C. J. Chin. Chem. Soc. 1997, 44, 321.

[9] Higa, M.; Yogi, S.; Hokama, K. Bull. Coll. Sci. Univer. Ryukyus. 1987, 44, 75.

[10] Kitajima, J.; Arai, M.; Tanaka, Y. Chem. Pharm. Bull. 1994, 42, 608.

[11] Kitajima, J.; Kimizuka, K.; Tanaka, Y. Chem. Pharm. Bull. 1998, 46, 1408.

[12] Kitajima, J.; Kimizuka, K.; Tanaka, Y. Chem. Pharm. Bull. 1999, 47, 1138.

[13] Pistelli, L.; Chiellini, E. E.; Morelli, I. Biochem. Syst. Ecol. 2000, 28, 287.

[14] Ragasa, C. Y.; Juan, E.; Rideout, J. A. J. Asian. Nat. Prod. Res. $1999,1,269$

[15] Kitajima, J.; Kimizuka, K.; Arai, M.; Tanaka, Y. Chem. Pharm. Bull. 1998, 46, 1647.

[16] Tuyen, N. V.; Kima, D. S. H. L.; Fong, H. S.; Soejarto, D. D.; Khanh,
T. C.; Tri, M. V.; Xuan L. T. Phytochemistry 1998, 50, 467.

[17] Awolola, G. V.; Chenia, H.; Baijnath, H.; Koorbanally, N. A. Rev. Bras. Farmacogn. 2017, 27, 599.

[18] Jain, R.; Rawat, S.; Jain, S. C. J. Pharm. Res. 2013, 6, 615.

[19] Kuo, P. C.; Chiu, C. C.; Shi, L. S.; Li, C. Y.; Wu, S. J.; Damu, A. G.; Wu, P.L.; Kuo, C. S.; Wu, T. S. J. Chin. Chem. Soc. 2002, 49, 113.

[20] Ahmed, W.; Khan A. Q.; Malik, A. Planta Med. 1988, 54, 481.

[21] Ramadan, M. A.; Ahmad, A. S.; Nafady, A. M.; Mansour, A. I. Nat Prod. Res. 2009, 23, 1218.

[22] Parveen, M.; Ghalib, R. M.; Mehdi, S. H.; Mattu, R. U. H.; Ali, M. J. Saudi. Chem. Soc. 2009, 13, 287.

[23] Mbosso, E. J. T.; Nguedia, J. C. A.; Meyer, F.; Lenta, B. N.; Ngouela, S.; Lallemand, B.; Mathieu, V.; Antwerpen, P. V.; Njunda, A. L.; Adiogo, D.; Tsamo, E.; Looze, Y.; Kiss R.; Wintjens, R. Phytochemistry 2012, 83, 95.

[24] Wang, Y. L.; Liang, H.; Zhang, Q. Y.; Cheng W.; Yi, S. R. Biochem. Syst. Ecol. 2014, 57, 210.

[25] Yessoufou, K.; Elansary, H. O.; Mahmoud, E. A.; Skalicka-Woźniak, K. Ind. Crop. Prod. 2015, 74, 752.

[26] Lopes, D.; Villela, C. T.; Kaplan M. A. C.; Carauta, J. P. P. Phytochemistry 1993, 34, 279.

[27] Hsia, T. C.; Liu, W. H.; Qu, W. W.; Luo, J.; Yin, M. C. Molecules 2014, 19, 19892

[28] Mu, D. W.; Guo, H. Q.; Zhou, G. B.; Li, J. Y.; Su, B. Int. J. Clin. Exp. Pathol. 2015, 8, 13864.

[29] Weber, D.; Zhang, M.; Zhuang, P.; Zhang, Y; Wheat, J.; Currie, G. Al-Eisawi, Z. Sage. Open. Med. 2014, 2, 2050312114551974.

[30] ] Narender, T.; Khaliq, T.; Singh, A. B.; Joshi, M. D.; Mishra, P.; Chaturvedi, J. P.; Srivastava, A. K.; Maurya R.; Agarwal, S. C. Eur. J. Med. Chem. 2009, 44, 1215.

[31] Ko B. S.; Kang, S.; Moon, B. R.; Ryuk J. A.; Park, S. Evid-Based Compl. Alt. 2016, 11, 1.

[32] Zhang, J.; Lu, X.; Fan, Q.; Xu, L.; Li, L.; Yue, Y.; Xu, Y.; Su, Y.; Zhang D.; Wang, L. Plos One 2015, 10, e0117400.

[33] Kim, S. J.; Cho, H. I.; Kim, S. J.; Kim, J. S.; Kwak, J. H; Lee, D. U.; Lee S. K.; Lee, S. M. J. Nat. Prod. 2014, 77, 2383.

[34] Badshah, H.; Ali, T.; Rehman, S. U; Amin, F. U.; Ullah, F.; Kim T. H.; Kim, M. O. J. Neuroimmune. Pharm. 2015, 11, 48.

[35] Qian, Y.; Huang, M.; Guan, T.; Chen, L.; Cao, L.; Han, X. J.; Huang, L.; Tang, X.; Li Y.; Sun, H. Eur. J. Pharmacol. 2015, 764, 298.

[36] Park, S. N.; Ahn S. J.; Kook, J. K. Braz. J. Microbiol. 2015, 46, 613

[37] Jamkhande, P. G.; Pathan S. K.; Wadher, S. J. Int. J. Mycoba. 2016, 5,417

[38] Lin, C. K.; Tseng, C.K.; Chen, K. H.; Wu, S. H.; Liaw C. C.; Lee, J. C. Brit. J. Pharmacol. 2015, 172, 4481.

[39] Cao, T. W.; Geng, C. A.; Jiang, F. Q.; Ma, Y. B.; He, K.; Zhou, N. J.; Zhang, X. M.; Zhou J.; Chen, J. J. Fitoterapia 2013, 89, 175.

[40] Saha, B.; Yamamoto, E. S.; Campos, B. L. S.; Jesus, J. A.; Laurenti, M. D.; Ribeiro, S. P.; Kallás, E. G.; Rafael-Fernandes, M.; Santos-Gomes, G.; Silva, M. S.; Sessa, D. P.; Lago, J. H. G.; Levy D.; Passero, L. F. D. Plos One 2015, 10, e0144946.

[41] Esposito, F.; Sanna, C.; Del Vecchio, C.; Cannas, V.; Venditti, A.; Corona, A.; Bianco, A.; Serrilli, A. M.; Guarcini, L.; Parolin, C.; Ballero M.; Tramontano, E. Pathog. Dis. 2013, 68, 116.

Received April 30, 2019 Accepted May 3, 2019 